\title{
The Availability of Specialist Doctors for the Reduction of Neonatal Deaths in 120 Municipal/District Locus in Indonesia
}

\author{
Teti Tejayanti ${ }^{1^{*}}$, Ika Saptarini ${ }^{1}$, Joko Irianto ${ }^{1}$ \\ ${ }^{I}$ Centre for Research and Development of Public Health Efforts, NIHRD, Ministry of Health, Jakarta, Indonesia \\ "Corresponding author. Email: teti.teja@yahoo.co.id
}

\begin{abstract}
Background: The Government of Indonesia has a policy of reducing neonatal deaths in 120 priority districts / cities. Information / evidence related to factors that can reduce neonatal mortality is still lacking, whereas neonatal deaths are 4-8 times greater than maternal deaths. Objective: evident a significant factor reducing neonatal mortality. Methods: Data is secondary data sourced, with the unit of analysis being municipal districts throughout Indonesia. The outcome variable is neonatal mortality per 1000 live births. The independent variable consists of the proportion of midwives, doctors, specialist doctors, health centers, availability of referral hospitals, chronic lack of energy nutrition in pregnant women, family planning, poverty, maternal death. Linear regression analysis. Results: Significant results in reducing mortality were maternal mortality ( $\mathrm{p}=0,000, \beta: 29$, CI: 0.009-0.016), specialist doctors $(\mathrm{p}=0,000, \beta: 22.4$, CI: $-0.010-$ $0.004)$, while the poverty factor protective $(p=0,019, \beta=21, \mathrm{CI}$ : $-0.100--0.009)$. Conclusions: each locus of the city must increase the availability of specialist doctors and prevent factors at risk of maternal death.
\end{abstract}

Keywords: neonatal mortality, doctors, health centers, indicator strategic

\section{INTRODUCTION}

The decrease in neonatal deaths is still an obstacle. At the global, in 2018, neonatal deaths increased to $47 \%$ from $40 \%$ in 1990 . Deaths that occurred within 28 days after birth or in the first month, reported around 7000 every day (Newborns: reducing mortality, WHO, 2019). The global target or SDGs, by 2030, reduce Neonatal Mortality Rate (NMR) to at least as low as 12 deaths per 1,000 live births. At present, Indonesia is approaching the target of 15 per 1,000 live births. (2017 IDHS). However, compared to neighboring countries with the same economic level, neonatal mortality in Indonesia is still higher. Neonatal mortality in Indonesia is 3 times higher than that of Thailand, 4 times that of Malaysia, 10 times that of Singapore and 2 times that of Brunei. (https://data.unicef.org/topic/child-survival/neonatalmortality/, 2019.)

The high neonatal mortality rate can have an impact on national losses, because of the loss of the embryo of the nation's successor. The costs absorbed for pregnancy and childbirth services provided by the Government of Indonesia are also not small, because there are around 5 million pregnant women every year in Indonesia. The high neonatal mortality rate is also a sign of suboptimal health service performance. Therefore, the reduction in neonatal deaths has become a priority program for Indonesia.

Various programs to reduce infant mortality have been carried out. Among them are improving the quality of antenatal care, delivery in health facilities and neonatal visits on the first three days, a week and a month after the baby is born. (Ministry of Health Strategic Plan). Although the coverage of the program has increased annually, the decline in neonatal deaths in the past 10 years has been very slow. So that efforts are needed to reduce mortality more strategically. The Government of Indonesia in 2020 and in the future has established locus of reduction in maternal and neonatal deaths in 120 districts / cities. In these areas more intervention was carried out with funding and health facilities.

From various intervention studies it was found that neonatal mortality was actually $75 \%$ avoidable (reference). However, funding intervention efforts and facilitation of health facilities are not enough, due to the fact that there are many factors that contribute to maternal and neonatal 
deaths. Information or analysis related to the reduction in neonatal deaths in Indonesia is still very little, even though several district/city reports, say neonatal deaths in Indonesia are almost 4-8 times maternal deaths. Therefore, this study aims to obtain significant factors in reducing neonatal mortality.

This study has limitations because it only uses variables that are used in determining the locus of reduction in maternal and neonatal mortality. That is because the availability of secondary data related to neonatal in the district scale is not widely available. Nevertheless, this will be minimized through the literature in the explanation. Research using these variables has never been done before.

\section{METHOD}

The population of this research is all municipal, cities in Indonesia. Data is secondary data sourced, with the unit of analysis being municipal districts throughout Indonesia. The outcome variable is neonatal mortality per 1000 live births. The source of the data of neonatal and maternal death comes from the district / city report compiled by the Ministry of Health's data and information center.

The independent variables consists of the proportion of midwives, doctors, specialist doctors, health centers, availability of referral hospitals ( data source from the Agency for the development of empowerment of human resources, Ministry of Health), chronic lack of energy nutrition in pregnant women, family planning, ( data source from the 2013 Basic Health Research, The National Institution of Health Research Development, Ministry of Health), poverty (data source from Central Bureau of Statistic). Analysis using linear regression.

\section{RESULTS AND DISCUSSION}

The Government of Indonesia has established 120 districts /cities as areas that will be a priority in reducing neonatal deaths by 2020 . We want to know which factors are predicted to have an impact on reducing neonatal mortality. The results show, the significant in reducing mortality were maternal mortality ( $\mathrm{p}=0,000, \beta: 29$, CI: 0.009-0.016), specialist doctors ( $\mathrm{p}=0,000, \beta: 22.4$, CI: $-0.010-0.004)$, while the poverty factor protective $(\mathrm{p}=0,019, \beta=21$, CI: 0.100- -0.009).

The results of the correlation between specialist doctors and neonatal deaths shows that as the number of specialist doctors increases, neonatal mortality decreases. Show the images below:

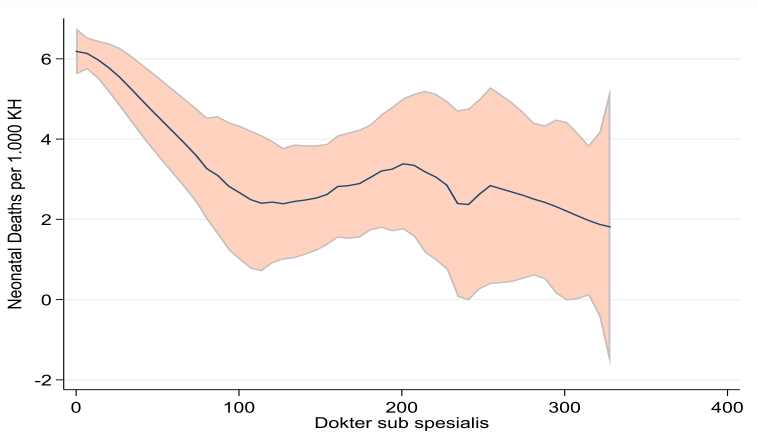

Figure 1. Correlation specialist doctors with neonatal death in Indonesia

Discussion

Maternal death is the most important factor in neonatal survival [1]. This is consistent with the other research $[2,3,4]$. Maternal deaths occur due to complications during pregnancy or childbirth or the puerperium. The most complications that can cause maternal death in Indonesia is the preeclampsia/eclampsia [5]. Most of these cases also because premature birth, where premature is still the highest cause of neonatal death [6].

The survival of the baby at birth is highly dependent on the completeness of the emergency services of the hospital and appropriate neonatal care [7]. That is, very dependent on medical/clinical help. Specialist's doctor is significant, will be describe the direct and indirect meaning. The direct meaning is for the survival of the baby, the role of the expert or specialist doctor is very important. Midwife, general practitioner does not have the leverage to survive a baby who is still vulnerable to outside influences.

Indirect meaning, specialist doctors describe the existing facilities specialist doctors usually are hospitals that are complete and competent. This means that districts that wish to reduce neonatal mortality must have a complete hospital for neonatal emergency assistance both in terms of personnel and infrastructure.

\section{CONCLUSION}

To reducing neonatal deaths, each locus of the city must increase the availability of specialist doctors and hospitals capable of providing emergency care appropriately. Prevent factors at risk of maternal death also have an impact on reducing neonatal mortality.

\section{ACKNOWLEDGMENT}

Thanks to the family health program for contributing data and analysis direction, Dr. dr. Vivi Setyawati who provided the opportunity to analyze the data, thanks to Ir. Doddy (Head of the Center for Public Health Efforts) who has given the opportunity to attend this International seminar. 


\section{REFERENCES}

[1] L. Foo, J. Tay, C. C. Lees;C. M. McEniery; 1.B. Wilkinson : Hypertension in Pregnancy: Natural History and Treatment Options;May, 2015.

https://link.springer.com/article/10.1007/s11 906-015-0545-2.

[2] The associations of parity and maternal age with small-for-gestational-age, preterm, and neonatal and infant mortality: a metaanalysis, Kozuki, N., Lee, A.C., Silveira, M.F. et al. BMC Public Health (2013) 13(Suppl 3): S2. https://doi.org/10.1186/1471-2458-13S3-S2.

[3] Aly, H., Moustafa, M., Amer, H. et al. Gestational Age, Sex and Maternal Parity Correlate with Bone Turnover in Premature Infants. Pediatr Res 57, 708-711 (2005) doi:10.1203/01.PDR.0000160591.70409.C8.

[4] Srour, Mahmoud A et al. "Prevalence of Anemia and Iron Deficiency among Palestinian Pregnant Women and Its Association with Pregnancy Outcome." Anemia vol. 2018 9135625. 24 Dec. 2018, doi:10.1155/2018/9135625

[5] Study of Maternal Deaths in the Five Regions, Disparity and Quality; Tejayanti $\mathrm{T}$, et al, NIHRD, Ministry of Health, UNFPA, 2012.

[6] Newborns: reducing mortality; Key facts; 19 Sepetember 2019; https://www.who.int/news-room/factsheets/detail/newborns-reducing-mortality.

[7] Maternal-fetal medicine specialist density is inversely associated with maternal mortality ratios; Scott A.SullivanMDaElizabeth G.HillPhDbRoger B.NewmanMDaM. KathrynMenardMDa; American Journal of Obstetrics and Gynecology; Volume 193, Issue 3, Supplement, September 2005, Pages 1083-1088. 